\title{
An evaluation of the Celloscope 401 electronic blood cell counter
}

\author{
T. R. J. LAPPIN, A. LAMONT, AND M. G. NELSON \\ From the Department of Haematology, Royal Victoria Hospital, Belfast
}

SYNOPSIS For counting erythrocytes the instrument was precise, with a mean coefficient of variation of $1.21 \%$.

Erythrocyte counts showed close agreement with results obtained on a Coulter A electronic counter of proven accuracy.

When the Celloscope 401 was modified by the manufacturers to eliminate electrical interference from other laboratory equipment, satisfactory precision and accuracy for white cell counting was obtained. Using cetrimide diluent the coefficient of variation was $1.6 \%$ but when using saponin/ saline diluent the coefficient of variation was $3.5 \%$. For leucocyte counting there was close agreement between duplicate tests performed on the Celloscope 401 and the Coulter S.

The instrument was capable of satisfactory precision and accuracy in platelet counting, provided that the sedimentation method was used to obtain a platelet-rich plasma. The best results were obtained if a two-step dilution was carried out with a first dilution in $10 \%$ EDTA and a second in $2.5 \mathrm{mM}$ cocaine in water. Using this method the precision study indicated a coefficient of variation of $3.11 \%$. Close agreement was obtained between platelet counts on the Celloscope 401 when compared with the results obtained either by phase-contrast microscopy or using another electronic counter.

Allowing for predilution and duplicate counts on each sample, the rate of throughput was approximately 32 samples per hour.

Throughout the test period, the instrument remained electronically and mechanically stable.

The Celloscope 401 is a semi-automatic particle counter based on the principle of modulation of electrical conductivity by the passage of particles in dilute suspension through an electrically sensed aperture. Blood samples are first diluted and the cell suspensions presented to the sample intake tube. An aliquot of diluted sample is aspirated into the system by suction derived from an accessory, electrically driven vacuum pump. By pressing the operational switch the counter is zeroed and the metered volume of dilute suspension is drawn through the electrically sensed aperture, tripping off the counting device. Each particle passing through the aperture causes an increase in resistance between the two electrodes thus generating a pulse. The instrument is so designed that every 64th pulse is registered on a mechanical counter. The volume of the sampled aliquot is automatically controlled by displacement of a column of mercury in a U-shaped tube. Counting of particles Received for publication 29 November 1971. begins when the mercury column touches the first and ends at the second of two contacts. The distance between these two contacts governs the metered volume. The optimum amplification and discriminator settings for the appropriate cells to be counted and for each diluent are indicated by coloured click-in markers.

In any electronic counter an error will be caused by two or more particles passing coincidentally through the 'sensing area' and this can be corrected in a number of ways. In the Celloscope every 64th particle is counted and no correction for coincidence is applied. The fact that all blood cell counts were linear over a wide range is an indication that no coincidence correction is necessary.

\section{Calibration}

Before evaluation the instrument was checked to see that it was counting correctly and that the counts were linear throughout the recommended ranges. 
A linearity check of the instrument for erythrocyte, leucocyte, and platelet counting was carried out by utilizing a cell suspension of high concentration, subsequently diluted in steps, and each suspension counted. The observed counts were then plotted against the calculated number of cells. Good linearity was achieved for the three cell components throughout the ranges tested: for erythrocytes up to $7.0 \times 10^{6}$, for leucocytes to $60.0 \times 10^{3}$, and for platelets to $5.0 \times 10^{5}$ per $\mu \mathrm{l}$. A non-linear portion was observed for platelet counts greater than $5.0 \times 10^{5}$ per $\mu 1$. This was due at least in part to inadequate response from the mechanical register. Suspensions giving counts beyond the straight line portion of the 'linearity courve' should be diluted until the results fall within the linear range.

Control settings should be correct, not only for the cell suspension being counted, but also for the particular diluent being used. In the Celloscope 401 the control settings for cell suspension and diluent are indicated by coloured click-in markers. If it is considered necessary to check the settings, this can be accomplished by using a particle suspension in the appropriate diluent and counting against varying amplification or discriminator settings. The resultant plots should contain characteristic plateaux from which the optimum settings can be checked or determined.

\section{Carryover}

In cell counting instruments such as the Celloscope, carryover may occur when cell particles adhere to the glass aperture tube and are thus transferred to the next diluted cell suspension. In order to investigate the degree of the cross contamination, a suspension of erythrocytes labelled with ${ }^{51} \mathrm{Cr}$ was diluted 1:80000 in the normal manner and the percentage transfer of the labelled cells was determined. The carryover was found to be less than $0.01 \%$, which is negligible.

\section{Erythrocyte Counts}

The diluting fluids for each method were filtered through a $0.8 \mu$ millipore filter before use in order to obtain a diluting fluid with a background of less than 4 counts per metered volume $(512 \mu \mathrm{l})$. In all cases the blank reagent count was subtracted from the total count to give the correct result.

Blood samples for erythrocyte counting were diluted 1:80000 using physiological saline which contained formaldehyde $(0.4 \% \mathrm{v} / \mathrm{v})$. The instrument settings were: amplifier in red click-in position (13) and discriminator in red click-in position (15). An $80 \mu$ aperture tube was used.

\section{Leucocyte Counts}

Blood samples were diluted in two steps for leucocyte counting. When cetrimide was used a 1:200 dilution was first prepared by adding $20 \mu \mathrm{l}$ of blood to $4 \mathrm{ml}$ of a diluent consisting of formalin $(0.4 \% \mathrm{v} / \mathrm{v})$ in physiological saline. This dilution remained stable for several hours. The initial $4 \mathrm{ml}$ dilution was then mixed with $12 \mathrm{ml}$ of a freshly prepared reagent which contained per litre cetrimide $(2 \%, 25 \mathrm{ml})$ glacial acetic acid $(5 \mathrm{ml})$, sodium nitrite $(1 \mathrm{~g})$, and formaldehyde saline $(970 \mathrm{ml})$, to give a final dilution of $1: 800$.

The amplifier was in the white click-in position (24) and the discriminator in the red click-in position (15) and an $80 \mu$ aperture tube was used.

When saponin diluent was used an initial 1:200 dilution was prepared by adding $20 \mu \mathrm{l}$ of blood to $4 \mathrm{ml}$ of a diluent which contained sodium chloride $(9 \mathrm{~g})$, EDTA di-sodium salt $(0.5 \mathrm{~g})$, formaldehyde $(40 \% \mathrm{v} / \mathrm{v}, 10 \mathrm{ml})$, and distilled water (to $1000 \mathrm{ml}$ ). This dilution remained stable for several hours. The initial $4 \mathrm{ml}$ dilution was mixed with a further $12 \mathrm{ml}$ of diluent and $0.1 \mathrm{ml}$ (2-3 drops) of saponin solution containing white saponin $(10 \mathrm{~g})$, ethyl alcohol $(10 \mathrm{ml})$; distilled water (to $100 \mathrm{ml}$ ) was added.

The amplifier was in the red click-in position (13), the discriminator was at 40 , and an $80 \mu$ aperture tube was used.

\section{Platelet Counts}

For platelet counting the manufacturers recommended sedimentation of blood, previously anticoagulated with polyvinyl/pyrrolidone and EDTA. Following a 1:3000 dilution of the platelet-rich plasma two counts were taken on the Celloscope: the first to count platelets and remaining erythrocytes, the second to count remaining erythrocytes only. The number of platelets was then calculated using the appropriate formula.

In our hands the results obtained by this method were unsatisfactory. An intensive study was mounted to investigate the various methods of preparation of platelet suspensions for counting on an electronic counter. The most satisfactory was found to be the technique which involved the preparation of plateletrich plasma and dilution in a non-aggregating reagent followed by a further dilution in a cocaine solution to cause platelet swelling.

Sedimentation of fresh blood samples was carried out according to the technique of Bull, Schneiderman, and Brecher (1965). An aliquot $(20 \mu 1)$ of plateletrich plasma was diluted with dipotassium EDTA $(10 \%, 10 \mathrm{ml})$. After gently mixing an aliquot $(2 \mathrm{ml})$ of the primary dilution was removed and placed in a 
plastic vial containing $10 \mathrm{ml}$ of $2.5 \mathrm{mM}$ cocaine. This gave a final platelet dilution of 1 in 3000 . The addition of this concentration of cocaine in water causes platelet swelling, giving more evenly sized particles which present a larger resistance between the instrument electrodes. The amplifier setting was 15 and the discriminator 13. A $48 \mu$ aperture tube was used.

The number of platelets may be calculated by using the formula:

$$
N=10\left(C_{1}-C_{2}\right)(100-H C t)
$$

where $C_{1}$ equals the platelet count values minus the blank values, $\mathrm{C}_{2}$ equals the contaminating erythrocyte count value minus the blank value, and $\mathrm{HCt}$ represents the haematocrit value.

When sufficient care was taken with the sedimentation procedure, it was possible to obtain plateletrich plasma free from contamination by erythrocytes, thus eliminating the need to change the aperture tube in order to count the erythrocytes. The calculation may then be abbreviated to:

$$
\mathrm{N}=10 \mathrm{C}_{1}(100-\mathrm{HCt})
$$

\section{Precision of Counting}

The precision of the Celloscope for counting each cell type was determined by repeated analysis of the same prediluted blood sample and the calculation of the standard deviation and coefficient of variation

\begin{tabular}{|c|c|c|c|c|}
\hline \multirow{3}{*}{$\begin{array}{l}\text { Dilution } \\
\text { in Saponin }\end{array}$} & \multicolumn{2}{|c|}{ With Other Equipment } & \multicolumn{2}{|c|}{ Without Other Equipment } \\
\hline & \multicolumn{2}{|c|}{ Coefficient of Variation (\%) } & \multicolumn{2}{|c|}{ Coefficient of Variation ( $\%)$} \\
\hline & Range & Mean & Range & Mean \\
\hline $1 / 800$ & $1 \cdot 55-15 \cdot 66$ & $7 \cdot 13$ & $1 \cdot 73-2 \cdot 71$ & $2 \cdot 18$ \\
\hline
\end{tabular}
(Table III).

Table I Precision of leucocyte counting by Celloscope 401 before modification
For erythrocyte counts the coefficient of variation (CV) ranged from 0.64 to 1.69 with a mean of 1.21 . Precision is therefore of the same order as reported for the Coulter model A (Nelson and Carville, 1962) and the Fisher Autocytometer (Lappin, Lamont, and Nelson, 1970).

Solutions containing cetrimide are known to cause electrode polarization. During evaluation it became apparent that cetrimide obtained from different sources caused varying degrees of polarization; that obtained from E. Merck, AG, Darmstadt, was found to be satisfactory. An investigation by Kvarstein (1967) confirmed the suitability of cetrimide in low concentrations as a white cell diluent for the Celloscope 101 . He also found that counts did not vary for a period of 24 hours. On the other hand, Degkwitz and Selle (1965) found that using a saponin solution there was a rapid decrease in the number of leucocytes at $26^{\circ}$ and over. Dilution with the cetrimide reagent would therefore appear to be the method of choice.

In this study of the Celloscope 401 suitably modified, the precision of leucocyte counting was better in the cetrimide diluent (mean CV, 1.60) than in saponin (mean CV 3.05).

The modified platelet counting method described above gave a range of $\mathrm{CV}$ from 1.53 to 4.59 , with a mean of $3 \cdot 11$.

\section{Accuracy of Counting}

To determine the accuracy of the instrument, blood samples were divided into two aliquots and submitted to analysis by the Celloscope and by acceptable standard methods.

A Coulter model A was used for erythrocyte counts, using the method of Brecher, Schneiderman, and Williams (1956) and a Coulter model $S$ for leucocyte counts. For platelet counting, the

\begin{tabular}{|c|c|c|c|c|c|}
\hline & \multirow[t]{2}{*}{ Erythrocytes } & \multicolumn{2}{|l|}{ Leucocytes } & \multicolumn{2}{|l|}{ Platelets } \\
\hline & & Cetrimide & Saponin & Cf Coulter $B$ & Cf Visual \\
\hline \multicolumn{6}{|l|}{ Mean Value } \\
\hline $\begin{array}{l}\text { Celloscope } \\
\text { Other methods }\end{array}$ & $\begin{array}{l}4 \cdot 499 \\
4 \cdot 489\end{array}$ & $\begin{array}{l}9 \cdot 342 \\
9 \cdot 394\end{array}$ & $\begin{array}{l}8 \cdot 374 \\
8 \cdot 518\end{array}$ & $\begin{array}{l}150 \cdot 52 \\
205 \cdot 68\end{array}$ & $\begin{array}{l}150 \cdot 52 \\
149 \cdot 84\end{array}$ \\
\hline \multicolumn{6}{|l|}{ Paired $t$ Test } \\
\hline $\begin{array}{l}\text { Degrees of freedom } \\
t \\
P\end{array}$ & $\begin{array}{l}49 \\
0 \cdot 487 \\
0 \cdot 6-0 \cdot 7\end{array}$ & $\begin{array}{l}49 \\
0.417 \\
0.6-0 \cdot 7\end{array}$ & $\begin{array}{l}49 \\
1 \cdot 52 \\
0 \cdot 1-0 \cdot 2\end{array}$ & $\begin{array}{l}24 \\
1 \cdot 576 \\
0 \cdot 1-0 \cdot 2\end{array}$ & $\begin{array}{l}24 \\
0.062 \\
>0.9\end{array}$ \\
\hline \multicolumn{6}{|l|}{ Correlation Test } \\
\hline $\begin{array}{l}\text { Degrees of freedom } \\
\mathbf{r} \\
\mathbf{P}\end{array}$ & $\begin{array}{l}48 \\
0.9681 \\
<0.001\end{array}$ & $\begin{array}{l}48 \\
0.9828 \\
<0.001\end{array}$ & $\begin{array}{l}48 \\
0.9935 \\
<0.001\end{array}$ & $\begin{array}{l}23 \\
0.9800 \\
<0.001\end{array}$ & $\begin{array}{l}23 \\
0.8875 \\
<0.001\end{array}$ \\
\hline Regression Equation & $\begin{array}{l}y=0.971 x+0.112 \\
\text { Sy } x=0.23\end{array}$ & $\begin{array}{l}y=1.017-0.111 \\
\text { Sy } x=0.89\end{array}$ & $\begin{array}{l}y=0.998+0.160 \\
S y \cdot x=0.52\end{array}$ & $\begin{array}{l}y=1 \cdot 316 x+7 \cdot 570 \\
S y \cdot x=31 \cdot 59\end{array}$ & $\begin{array}{l}y=0.885 x+16.633 \\
S y \cdot x=54.35\end{array}$ \\
\hline
\end{tabular}
Celloscope 401 was compared with two separate and

Table II Comparison of results with Celloscope and other methods 
distinct counting techniques: (1) by visual counting using phase contrast microscopy, and (2) by electronic counting using a Coulter model B. Table II shows that there was good agreement between both methods in each comparison. No significant difference $(P<0.05)$ between the means of each series was detected. Furthermore each pair of determinations was found to be strongly associated, in a positive sense, when the coefficients of correlation and regression equations were calculated.

\section{Mechanical and Electronic Stability}

During the evaluation period three Celloscope 401 instruments were tested. The first instrument gave satisfactory results for erythrocyte and platelet counting but was unsatisfactory for counting leucocytes. A precision study gave a mean coefficient of variation of $7 \cdot 13 \%$ (see Table I).

The instrument was known to be susceptible to electronic interference from other pieces of laboratory equipment. This caused only a small percentage error during erythrocyte and platelet counting but this error was significantly greater during leucocyte counting where fewer cells are counted.

After consultation with the manufacturers the instrument was modified by lowering the gain on both the amplification and discriminator circuits. This resulted in a much higher degree of precision in leucocyte counting and greatly improved accuracy.

\begin{tabular}{|c|c|c|c|}
\hline & $\begin{array}{l}\text { Range of } \\
\text { Determination }\end{array}$ & $\begin{array}{l}\text { Range of } \\
\text { Coefficient of } \\
\text { Variation }\end{array}$ & $\begin{array}{l}\text { Variation (\%) } \\
\text { Mean }\end{array}$ \\
\hline $\begin{array}{l}\text { Erythrocytes } \\
\text { Leucocytes in }\end{array}$ & $1.43-5.95$ & $0.64-1.69$ & $1 \cdot 21$ \\
\hline $\begin{array}{l}\text { Cetrimide diluent } \\
\text { Saponin diluent } \\
\text { Platelets }\end{array}$ & $\begin{array}{c}5 \cdot 12-33 \cdot 18 \\
3 \cdot 28-32 \cdot 93 \\
71 \cdot 9-376 \cdot 2\end{array}$ & $\begin{array}{l}1 \cdot 03-2 \cdot 22 \\
1 \cdot 72-4 \cdot 39 \\
1 \cdot 53-4 \cdot 59\end{array}$ & $\begin{array}{l}1.60 \\
3.05 \\
3 \cdot 11\end{array}$ \\
\hline
\end{tabular}

Table III Precision of the Celloscope 401 after modification

During the period of study no trouble was encountered with either the mechanical or hydraulic parts of the instrument.

\section{Rate of Throughput}

The Celloscope requires about $\mathbf{4 0}$ seconds to count a prediluted cell suspension, although it varies slightly with the metering unit and aperture tube being used. The throughput rate is of the order of 50 tests per hour if it is assumed that preparation of the dilution requires 30 seconds and a single determination is made. The rate is approximately 32 \% tests per hour if duplicate counts are performed.

\section{Capital and Running Costs}

The cost of the Celloscope 401, complete for counting the three cellular blood components, is on approximately $£ 700$.

The cost of reagents, disposable plastic tubing, and $30 \mathrm{ml}$ plastic containers per hundred determinations, is approximately $65 \mathrm{p}$ for erythrocyte counting, $35 \mathrm{p}$ for leucocyte counting, and $£ 4.85$ for platelet counting.

This study was undertaken at the request of the Laboratory Equipment and Methods Advisory Group of the Department of Health and Social Security, London.

We are grateful to Messrs Ljungberg \& Company Limited and Messrs Grant Instruments (Cambridge) Limited, for making the Celloscope 401 available for evaluation.

\section{References}

Brecher, G., Schneiderman, M., and Williams, G. Z. (1956). Evaluation of el ectronic red blood cell counter. Amer. J. clin. Path., 26, 1439-1449.

Bull, B. S., Schneiderman, M. A., and Brecher, G. (1965). Platelet counts with the Coulter counter. Amer. J. clin. Path., 44, 678-688.

Degkwitz, R., and Selle, H. (1965). Temperaturschwankungen als, Fehlerquelle bei der automatischen Leukocytenzăhlung mit, dem Coulter Ccunter. Klin. Wschr., 43, 1268-1271.

Kvarstein, B. (1967). The use of an electronic particle counter (Celloscope 101) for counting leucocytes. Scand. J. clin. Lab. Invest., I 19, 196-202.

Lappin, T. R. J., Lamont, A., and Nelson, M. G. (1969). An evaluation of the AutoAnalyzer SMA-4. J. clin. Path., 22, 11-18.

Lappin, T. R. J., Lamont, A., and Nelson, M. G. (1970). Evaluation $\mathscr{O}$ of the Fisher Autocytometer. Lab. Pract., 19, 907-908, and 924. N

Nelson, M. G., and Carville, J. M. (1962). Blood cell counting: a O comparison of the E.E.L. and Coulter machines. Irish J. med. స్ Sci., 447-456. 